\title{
Case Report \\ Congenital Complete Atrioventricular Block and Dilated Cardiomyopathy: New Light for an Old Disease
}

\author{
Mariana Paiva, Vania Ribeiro, Raquel Garcia, Sandra Amorim, Manuel Campelo, \\ Elisabete Martins, Brenda Moura, Jose Cardoso, and M. Júlia Maciel \\ Cardiology Department, Centro Hospitalar São João, 4200-319 Porto, Portugal
}

Correspondence should be addressed to Mariana Paiva, marianampaiva@gmail.com

Received 5 April 2012; Accepted 18 July 2012

Academic Editors: H. Kitaoka, K. Nikus, and J. Peteiro

Copyright (C) 2012 Mariana Paiva et al. This is an open access article distributed under the Creative Commons Attribution License, which permits unrestricted use, distribution, and reproduction in any medium, provided the original work is properly cited.

\begin{abstract}
We present a case of a patient with known complete congenital atrioventricular block (CAVB) since the age of 7 years old that developed dilated cardiomyopathy ten years after VVI-R pacemaker implantation. He presented severe biventricular dysfunction and was symptomatic despite optimal medical therapy. Cardiac resynchronization therapy was used, and he showed clinical and electrocardiographic improvement a month later.
\end{abstract}

\section{Case Report}

A 7 -year-old boy was sent, in 1997, to a pediatric cardiology outpatient clinic, due to a slow heart rate and exercise intolerance. His EKG showed sinus rhythm, $44 \mathrm{bpm}$, complete atrioventricular block (CAVB), and left bundle branch block (Figure 1). His TTE showed no structural abnormalities. Exercise treadmill test revealed an inappropriate chronotropic response to exercise. The 24-hour Holter test confirmed permanent CAVB and the absence of other abnormalities.

At age 11, for worsening of exercise tolerance, a VVI$\mathrm{R}$ pacemaker was implanted (Figure 2 ). He was completely asymptomatic, and by 19 years old the TTE showed a severe LVSD, with slight increase of LV diameter and mild right ventricular systolic dysfunction; he started lisinopril and bisoprolol.

By age 21, he became symptomatic in NYHA class IV and hypotensive. BNP and D-dimers levels were high. The EKG was similar to previous ones, and the TTE showed severe right chamber dilatation (LVEDD of $65 \mathrm{~mm}$ ), severe biventricular dysfunction (LVEF 21\%), severe tricuspid regurgitation and estimated PASP of $62 \mathrm{mmHg}$ (Figure 3). A chest CT scan showed signs of chronic pulmonary embolism. Full dose enoxaparin was started, and he was hospitalized.

He improved clinically, although maintaining mildto-moderate exertion dyspnea. TEE showed no left atrial appendage thrombus, and the genetic prothrombotic analyses revealed a deficiency of C-protein.

As he was lifelong pacemaker dependent, with severe biventricular dysfunction and being symptomatic despite medical therapy, VVI-R was upgraded to CRT-D. QRS complex became narrower (from 174 to $126 \mathrm{mseg}$ ) (Figure 4). He was discharged on candesartan, bisoprolol, spironolactone, warfarin, and furosemide.

One month after, in NYHA class II, TTE showed a slight improvement in left ventricular function, while maintaining right chamber dilation and pulmonary hypertension (PASP $67 \mathrm{mmHg}$ ).

\section{Discussion}

This case illustrates the complexity of management of patients with congenital CAVB. The diagnosis can be quite challenging and is more commonly done during childhood, even though a timeline for diagnosis can begin in uterus until late adulthood. The most common signs are bradycardia and inadequate chronotropic response to a stress test. There is a wide variability in symptom presentation from fatigue, exercise intolerance, and the most preoccupating syncope and sudden death. The evolution to dilated cardiomyopathy is well documented and not uncommon [1], although different mechanisms have been proposed and reported. In 


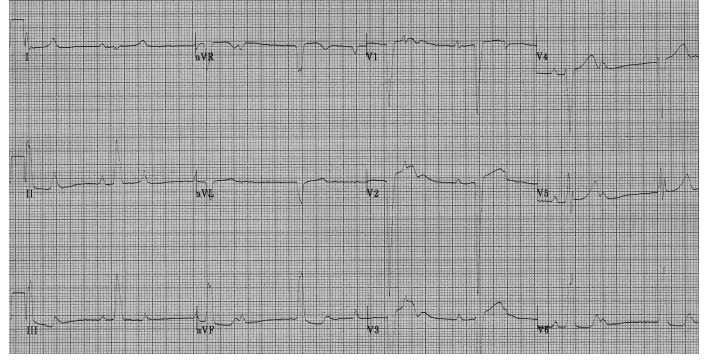

FIGURE 1: EKG showing complete heart block with ventricular escape rhythm.

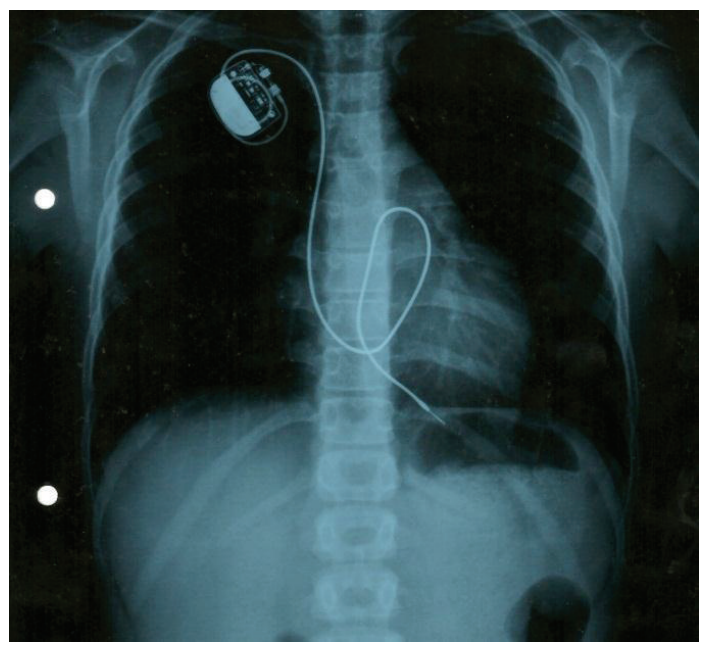

FIgure 2: Thorax X-ray after VVI-R implantation.

the case of our patient, the development of pulmonary hypertension due to chronic thromboembolism was a complication factor and certainly an occurrence that would be responsible for a worse outcome. Approximately $40 \%$ of patients with protein $\mathrm{C}$ deficiency present with evidence of pulmonary embolism, and roughly $60 \%$ suffer recurrent thrombosis if anticoagulation is discontinued. Even though recent reports have demonstrated the good overall prognosis associated with $\mathrm{CAVB}$, the presence of maternal autoantibodies (anti-Ro and anti-LLA) [2] at the time of diagnosis has been associated with a worse outcome, and the deleterious effect of right ventricular pacing is still in debate $[3,4]$. This sets the discussion on when is the ideal time for pacemaker implantation. Indications for pacemaker implantation are the presence of symptoms, including exercise intolerance, slow ventricular escape rhythms, and previous Stoke-Adams attacks in order to prevent sudden death occurrence. For the first time, in early 2004, the deleterious effects of right ventricular pacing are recognized as a cause for dilated cardiomyopathy, and this adds for the controversy on prophylactic pacemaker in these patients. Despite this acknowledgment, it has been observed that these patients tolerate well lifelong pacing, and the evolution to dilated cardiomyopathy has been related to other etiologies usually related to the disease itself [2].

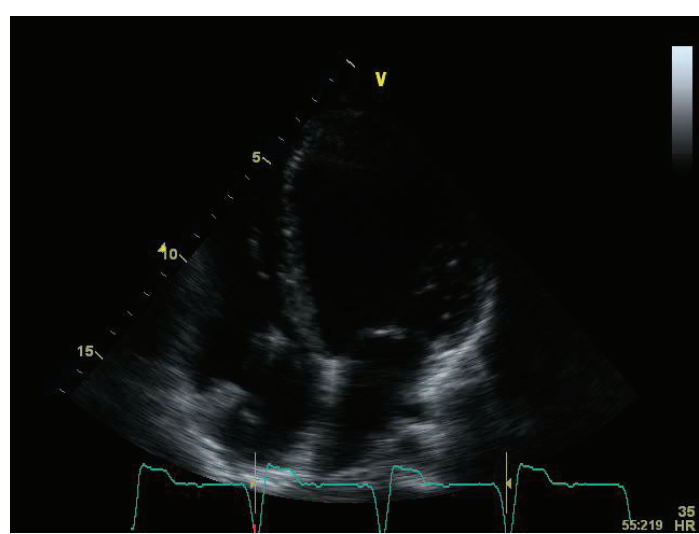

Figure 3: ETT showing dilatation of left ventricle.

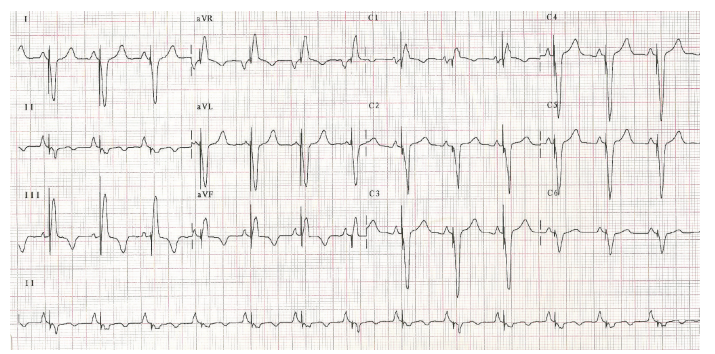

Figure 4: ECG after CRT implantation.

The implantation of biventricular pacing in some selected cases might be the solution after the tragic development to dilated cardiomyopathy in these patients $[3,5]$.

\section{Conflict of Interests}

The authors declare that they have no conflict of interests.

\section{References}

[1] F. E. A. U. Ten Cate, J. M. P. J. Breur, M. I. Cohen et al., "Dilated cardiomyopathy in isolated congenital complete atrioventricular block: early and long-term risk in children," Journal of the American College of Cardiology, vol. 37, no. 4, pp. 1129-1134, 2001.

[2] A.-E. Baruteau, S. Fouchard, A. Behaghel et al., "Characteristics and long-term outcome of non-immune isolated atrioventricular block diagnosed in utero or early childhood: a multicentre study," European Heart Journal, vol. 33, no. 5, pp. 622-629, 2012.

[3] J. B. Thambo, P. Bordachar, S. Garrigue et al., "Detrimental ventricular remodeling in patients with congenital complete heart block and chronic right ventricular apical pacing," Circulation, vol. 110, no. 25, pp. 3766-3772, 2004.

[4] C. S. Chronister, "Congenital complete atrioventricular block in a young man: a case study," Critical Care Nurse, vol. 29, no. 5, pp. 45-56, 2009.

[5] J. P. Piccini, A. F. Hernandez, D. Dai et al., "Use of cardiac resynchronization therapy in patients hospitalized with heart failure," Circulation, vol. 118, no. 9, pp. 926-933, 2008. 


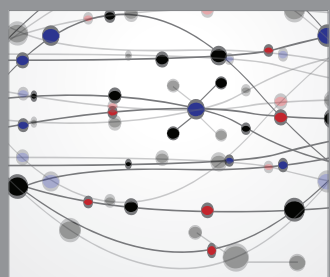

The Scientific World Journal
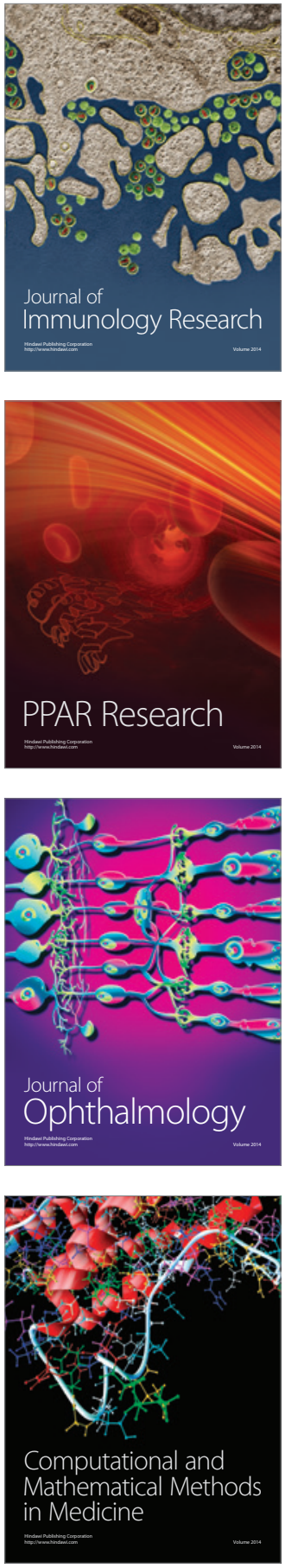

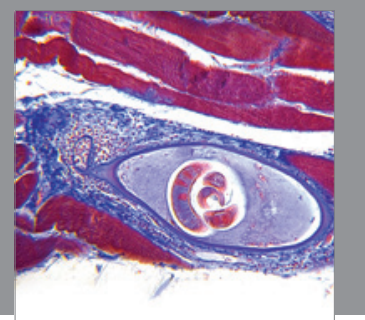

Gastroenterology

Research and Practice
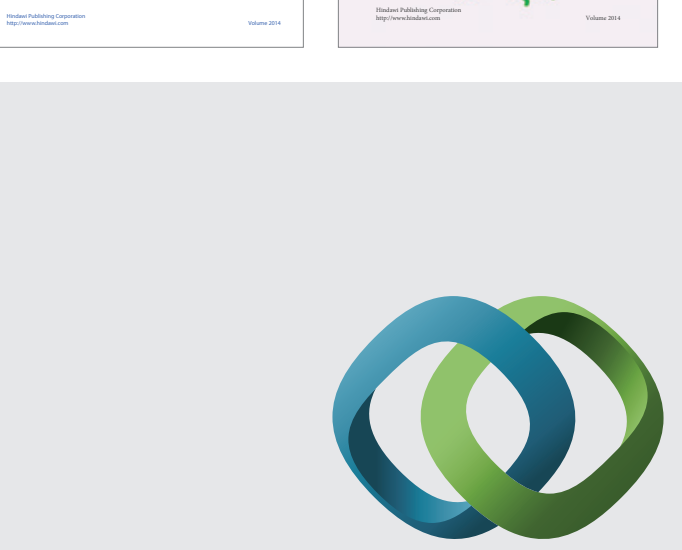

\section{Hindawi}

Submit your manuscripts at

http://www.hindawi.com
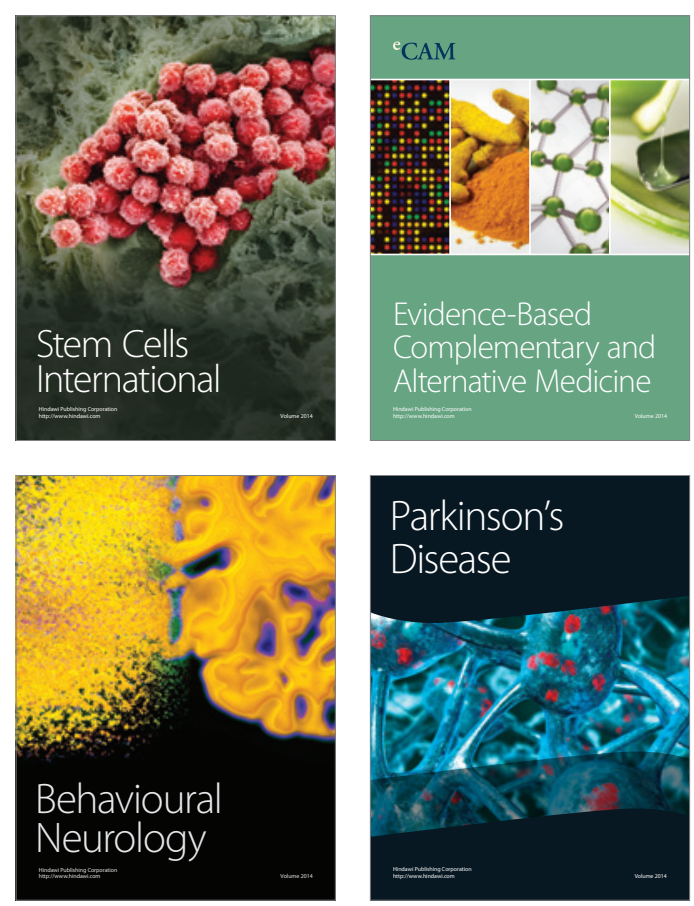

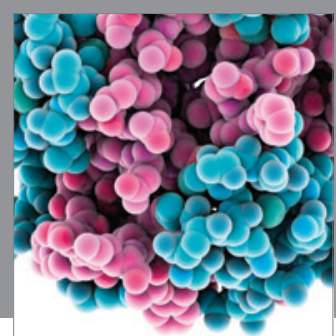

Journal of
Diabetes Research

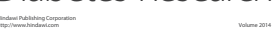

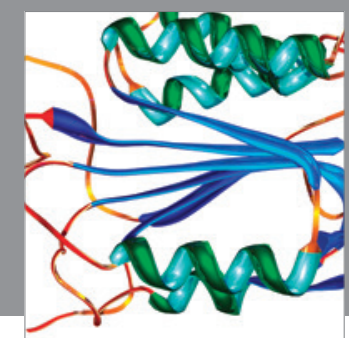

Disease Markers
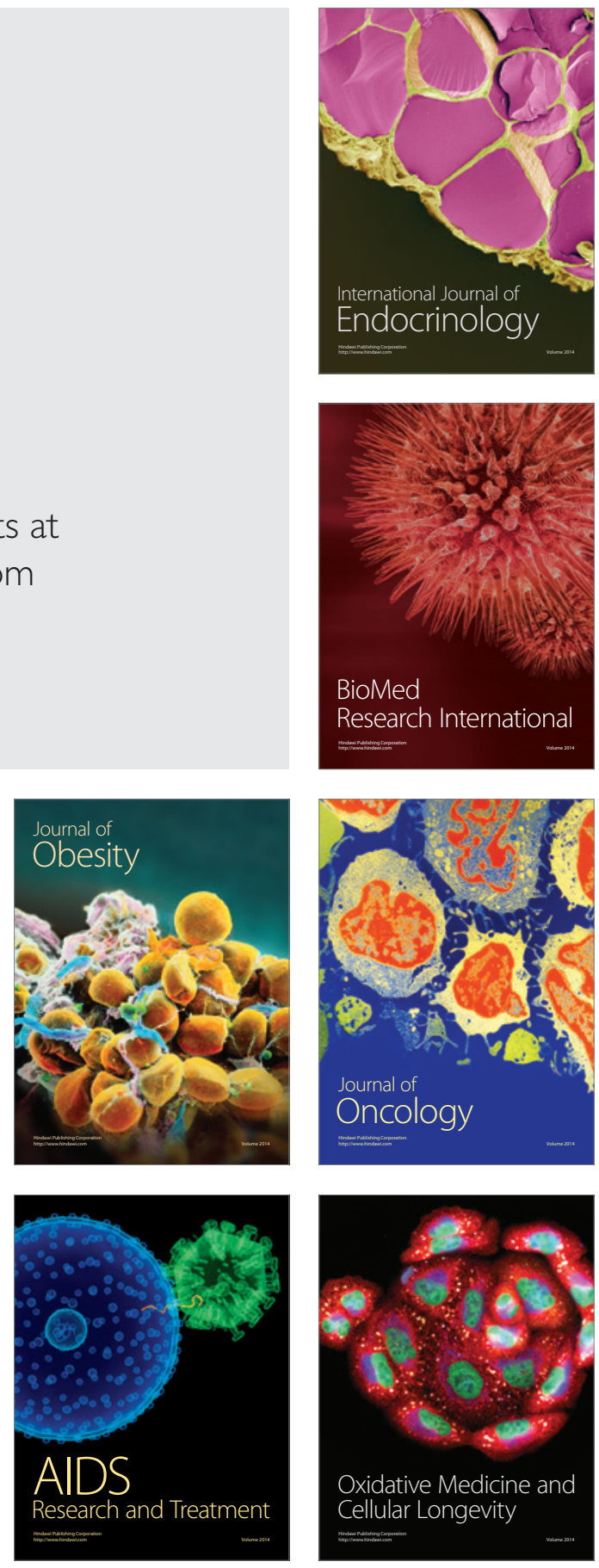